\title{
Prevalence of congenital anomalies in a tertiary care centre in North Kerala, India
}

\author{
Jayasree S., Smitha D'Couth*
}

Department of Obstetrics and Gynecology, Government Medical College, Kozhikode, Kerala, India

Received: 22 January 2018

Accepted: 27 January 2018

\section{*Correspondence:}

Dr. Smitha D'Couth,

E-mail: smithasebin@gmail.com

Copyright: (C) the author(s), publisher and licensee Medip Academy. This is an open-access article distributed under the terms of the Creative Commons Attribution Non-Commercial License, which permits unrestricted non-commercial use, distribution, and reproduction in any medium, provided the original work is properly cited.

\begin{abstract}
Background: Congenital anomalies have emerged as an important cause for neonatal morbidity and mortality. The prevalence as well as pattern of anomaly varies from place to place. Literature search reveals that India has the highest number of children with birth defects.

Methods: This is a cohort study conducted in the Department of Obstetrics and Gynecology during the period 20092015. All mothers admitted with congenital structural defects to the fetus diagnosed by imaging and those who delivered anomalous babies were included in this study. The anomalies were classified based on ICD-10 system.

Results: There were a total of 911 anomalous babies born during the study period of which 554 were males and 338 were females.19 babies had ambiguous genitalia. Anomalies were more common in multigravidae and in mothers of age group 20-29 years. Maximum number of babies were born between 37-40weeks. Maternal diabetes was associated with increased incidence of anomalies. Most common system involved was urinary system followed by musculoskeletal system.

Conclusions: The prevalence of structural anomalies in the present study is $0.84 \%$. Patients with risk factors for anomalies should undergo pre-pregnancy counselling. Routine antenatal anomaly screening with ultrasound before viability should be done for all patients so that early termination of lethal anomalies can be done.
\end{abstract}

Keywords: Congenital anomaly, Pattern of prevalence, Risk factors

\section{INTRODUCTION}

Congenital anomalies have emerged as an important cause of infant morbidity and mortality worldwide. ${ }^{1}$ In the Global Burden of Disease study 2013 congenital anomalies are included in the top ten causes for mortality in children less than five years of age. ${ }^{2}$ According to the World Health Organization (WHO) document of 1972, the term congenital malformations should be confined to structural defects at birth. ${ }^{3}$ However, as per the more recent WHO fact-sheet of September 2016, congenital anomalies are defined as structural or functional anomalies (for example, metabolic disorders) that occur during intrauterine life and can be identified prenatally, at birth, or sometimes may only be detected later in infancy. ${ }^{4}$

The world wide incidence of congenital anomalies is estimated as $3-7 \%$, but it may vary between countries. ${ }^{5}$ It is difficult to get the actual incidence of birth defects as two third of them are not recognized at birth. Every year an estimated 7.9 million children are born with a serious birth defect, 3.3 million children (under five years) die from birth defects, and 3.2 million who survive may develop a disability later in the life. ${ }^{6}$ In low and middle income countries especially in the rural areas still communicable diseases and malnutrition contribute major part of infant mortality. But as the socioeconomic status improves, there is an epidemiological transition in the 
rate as well as cause of infant mortality. Immunization and use of broad spectrum antibiotics along with improvement in nutritional status have reduced the problem in low and middle income countries also. In this scenario birth defects will begin to emerge as one of the major contributor of infant morbidity and mortality. ${ }^{7} \mathrm{~A}$ large number of congenital malformations are incompatible with life. But children with congenital defects may develop long term disability which can cause a significant impact on individuals, families, healthcare system and societies. ${ }^{4} 40 \%$ of pediatric surgery admissions are contributed by structural birth defects. ${ }^{8}$ As the healthcare facilities improves life expectancy of children with congenital anomalies also increases with all its consequences.

The birth prevalence of congenital anomalies in the developing countries is actually underestimated due poor registry, lack of diagnostic techniques and their reliability. ${ }^{9}$ Like other low and middle income countries, still congenital anomalies are not considered as a major problem in India. But literature search reveals that India has the highest number of children with birth defects. ${ }^{10}$ About $2.5 \%$ neonates at birth are affected by birth defects which accounts for $8-15 \%$ of perinatal deaths and 13$16 \%$ of neonatal deaths in India. ${ }^{11,12}$

About $60 \%$ of major malformations have no recognized aetiology. They can occur as an inherent genetic condition, poor diet, exposure to environmental toxins or infectious agents. Thus, we require systematic data on the magnitude of congenital anomalies, their pattern of prevalence, healthcare impact and impact on neonatal health. Prevalence studies give an idea about the pattern of occurrence of anomalies in different places, changes over a period of time and also give some clues to identify the aetiology.

\section{METHODS}

This is a cohort study conducted in the Department of Obstetrics and Gynecology, Government Medical College Kozhikode; North Kerala during the period 2009 to 2015. This is one of the centres in Asia having maximum number of deliveries.

\section{Inclusion criteria}

- Antenatal women registered in /referred to our outpatient department who were detected to have structural anomalies to foetus after gestational age of 24 weeks (calculated by LMP and /or first trimester USG).

- All women who gave birth to babies with structural defect after 24 weeks of gestational age.

\section{Data collection}

- From antenatal records

- Personal interview with a proforma
- From labour records

- Direct observation of the baby.

Those with structural anomalies in USG and foetal echo were analyzed. Data regarding maternal risk factors including maternal age, diseases, drug intake, history of consanguinity etc were collected. Gestational age at which delivery had occurred, sex and weight of the baby also noted. The anomalies detected either with imaging or by physical examination at birth were classified based on ICD-10 system.

\section{RESULTS}

There were 1,08,024 babies born during the observational period of 7 years. 911 babies had congenital structural anomalies. The prevalence rate of structural birth defects after 24 weeks of gestation is $0.84 \%$. $60.8 \%$ (554) of the anomalous babies were males and $37.1 \%$ (338) were females. $2.1 \%$ (19) had ambiguous genitalia. Among male children the incidence is $1.04 \%$ which is significantly more than female children $(0.62 \%)$ (Figure 1).

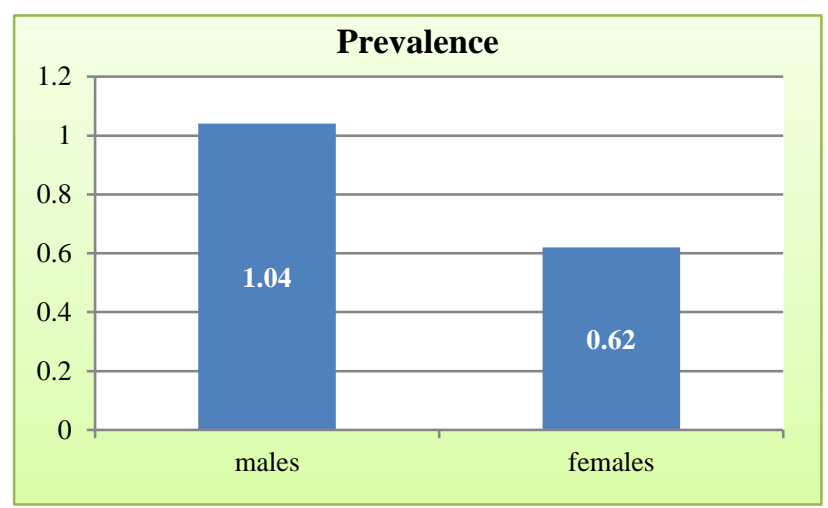

Figure 1: Prevalence of anomalies in males and females.

Out of 911 babies $45.66 \%$ were born to primigravidae, $52.9 \%$ were born to multigravidae, and $1.4 \%$ were born to grand multigravidae (Figure 2).

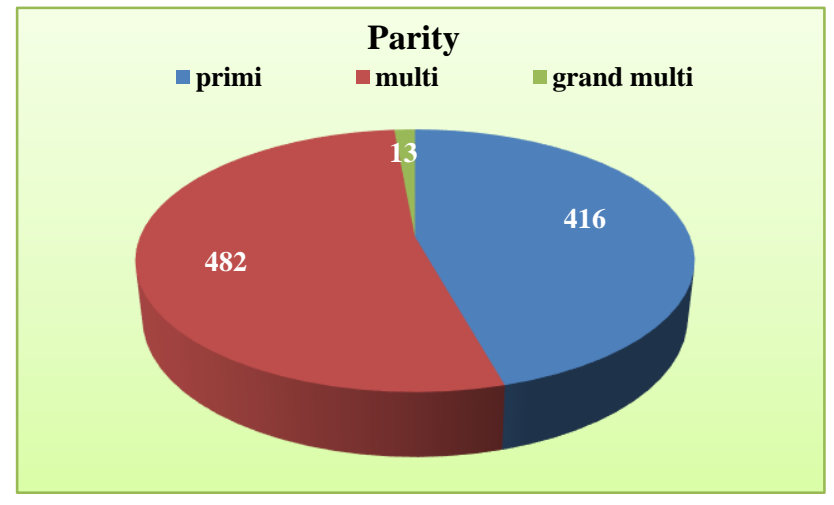

Figure 2: Distribution of anomalies in different parities. 
$20.3 \%$ of babies were born before 34 weeks, $10.5 \%$ were born between 34-37 weeks. Majority were born between $37-40$ weeks $(52.2 \%) .16 .9 \%$ of the babies were born after 40 weeks (Figure 3 ).

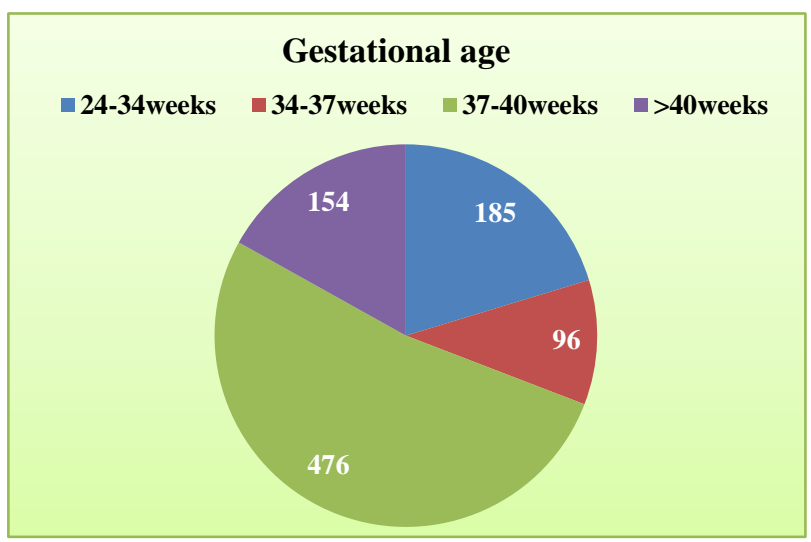

Figure 3: Distribution of anomalies in different gestational ages.

When the birth weight was analyzed majority of them were having birth weight between 2.5 and $4 \mathrm{~kg}(50.8 \%)$. $29.1 \%$ were between $1.5-2.49 \mathrm{~kg}$. $18.8 \%$ of the babies had birth weight less than $1.5 \mathrm{~kg} .1 .09 \%$ were weighing more than $4 \mathrm{~kg}$ (Figure 4).

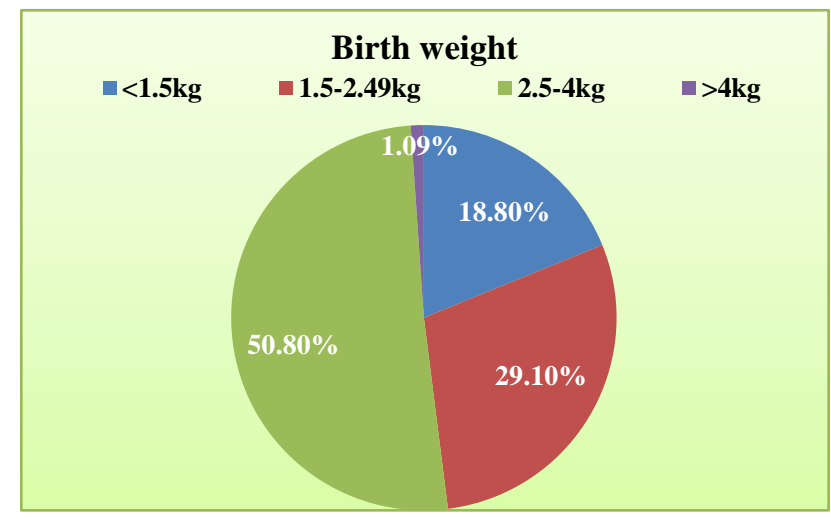

Figure 4: Distribution of anomalies in different birth weight.

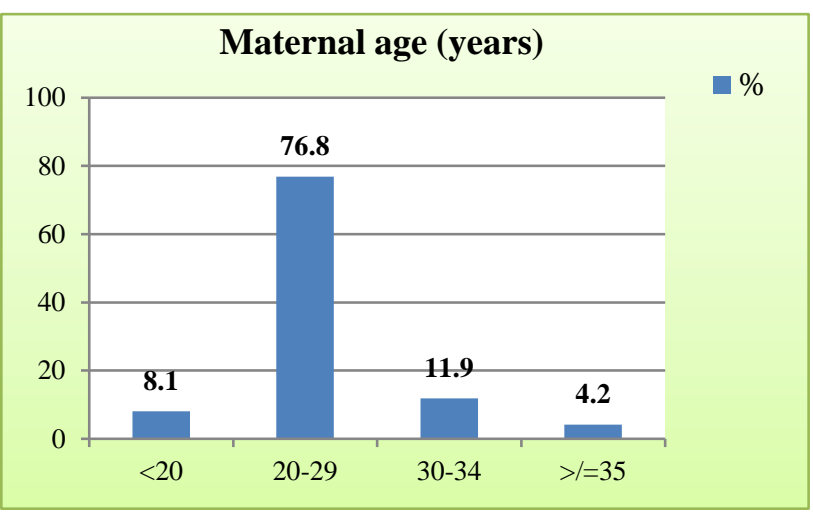

Figure 5: Distribution of anomalies in different maternal age groups.
Regarding maternal age, majority of the anomalies were seen in the age group 20-29 years (76.8\%). Only $8.1 \%$ was seen in those who were less than 20 years and $4.2 \%$ was seen in women who were more than 35 years (Figure $5)$.

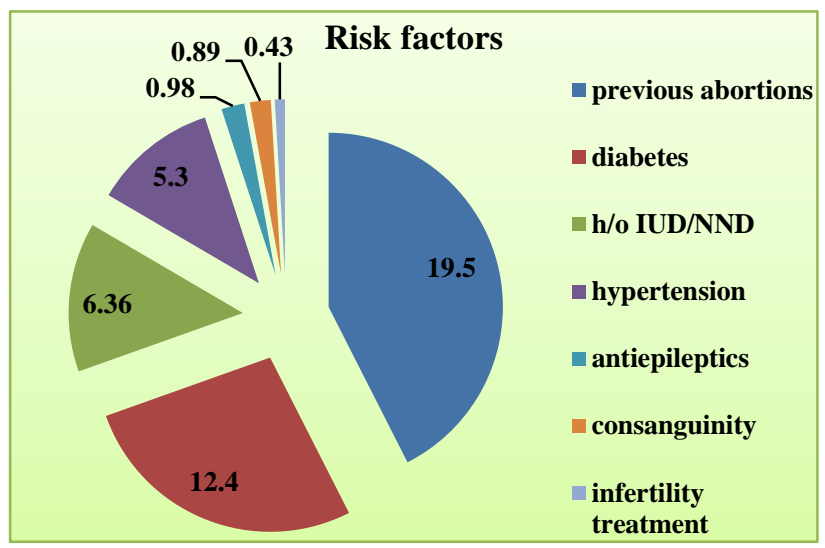

Figure 6: The maternal risk factors in congenital anomalies.

Out of 911 cases 178 women had history of previous abortions (19.5\%) and 61 women (6.36\%) had bad obstetric outcome like intrauterine demise and neonatal death. $5.3 \%$ women were hypertensive and $12.4 \%$ were diabetic. $0.98 \%$ were taking drugs for epilepsy. Only in less than $1 \%$ there was history of consanguinity. $0.43 \%$ had history of taking treatment for infertility (Figure 6).

Breech presentation was associated with increased prevalence of anomalies. Out of 911 cases 103 were in breech presentation. The prevalence of structural anomalies in breech presentation was 2.8\%. 33 babies with anomalies were born as one on the twins. 191 babies were born dead ie $20.9 \%$ and 51 babies had neonatal death $(5.6 \%)$. Out of a total of 2234 intra uterine demises during the study period 191 had congenital anomalies i.e. $8.5 \%$. Out of 1300 neonatal deaths in the study period, 51 babies $(3.92 \%)$ had congenital anomalies.

Table 1: System wise distribution of anomalies.

\begin{tabular}{|c|c|c|c|}
\hline System involved & $\begin{array}{l}\text { ICD-10 } \\
\text { Classification }\end{array}$ & $\begin{array}{l}\text { No. of } \\
\text { cases }\end{array}$ & $\%$ \\
\hline Nervous system & $1.1(\mathrm{Q} 00-07)$ & 198 & 21.73 \\
\hline Circulatory system & $1.3(\mathrm{Q} 20-\mathrm{Q} 28)$ & 93 & 10.2 \\
\hline Respiratory system & $1.4(\mathrm{Q} 30-\mathrm{Q} 34)$ & 25 & 2.74 \\
\hline Digestive system & $1.5(\mathrm{Q} 35-\mathrm{Q} 45)$ & 158 & 17.34 \\
\hline Genital system & $1.6(\mathrm{Q} 50-\mathrm{Q} 56)$ & 33 & 3.62 \\
\hline Urinary system & 1.7 (Q60-Q64) & 271 & 29.75 \\
\hline $\begin{array}{l}\text { Musculoskeletal } \\
\text { system }\end{array}$ & 1.8 (Q65-Q79) & 220 & 24.15 \\
\hline Others & $1.9(\mathrm{Q} 80-\mathrm{Q} 89)$ & 62 & 6.81 \\
\hline
\end{tabular}

The system wise distribution of structural anomalies as per the ICD 10 system (WHO 2010) are given in the Table 1. 
Most common among the anomalies were those affecting the renal system. $271(29.75 \%)$ babies had renal anomalies. The next common was the anomalies affecting skeletal system. 220 babies $(24.15 \%)$ had deformities of skeletal system. Nervous system involvement was seen in $198(21.73 \%)$ babies.

In renal system out of 271 cases, 112 had hydronephrosis 22 had pelviureteric junction obstruction and 31 had pelvicalyceal system dilatation i.e. $60.89 \%$ of the renal anomalies were obstructive type. In skeletal system anomalies congenital diaphragmatic hernia contributed $25.9 \%$ (57 cases). CTEV was seen in $12.4 \%$ (26 cases). Skeletal dysplasia was seen in $4.8 \%$ (10 cases). In gastro intestinal system anomalies, cleft lip and cleft palate were the most common type-47 cases $(29.75 \%)$. Next were duodenal atresia and imperforate anus 13cases (7.73\%) each. In nervous system most common anomaly was hydrocephalus (28.3\%). $19.7 \%$ had Dandy Walker syndrome. Meningomyelocoele was seen in $12.12 \%$. Anencephaly was seen in 24 cases. In cardiovascular system most common anomaly was hypoplasia of one of the ventricles.

\section{DISCUSSION}

The prevalence of structural anomalies in present study is $0.84 \%$. Studies from different parts of India reported incidence of $1.9 \%$, and $1.25 \% .^{13,14}$ There are other reports from different parts of the world representing different frequency of congenital malformations. ${ }^{15,16}$ The prevalence is low in this study because most of the lethal anomalies detected prior to 20 weeks of gestation who had undergone medical termination were not included in this study and only structural anomalies were analyzed here. The incidences of birth defect are three times higher in the hospitals where autopsies are performed. Some centres reported a higher incidence of congenital malformations due to more autopsy rates. ${ }^{17,18}$ In England and US, the prevalence is $2 \%$ and $2-3 \%$ respectively. ${ }^{19}$

There are a lot of studies to support the increased incidence of congenital anomalies in advanced maternal age. ${ }^{20-23}$ But as the maximum number of deliveries occur in the age group 20-29 years, more anomalies were detected in babies born to mothers of this age group. In our study $76.8 \%$ of the anomalies were from this maternal age group.

In the present study it is observed that congenital anomalies are more prevalent in male babies compared to females. $60.8 \%$ of the anomalous babies were males. This was similar to other studies. ${ }^{14,18}$ It may be because of the fact that the females were affected with more lethal congenital malformations and could not survive up to an advanced gestation. Swain, Savaskar and Padma observed that congenital anomalies were more in multigravidae than in primigravidae. ${ }^{21,22,24}$ It was significantly seen to be higher in mothers of gravidity 4 or more. ${ }^{18,25}$ This study showed that $52.9 \%$ of the anomalies were in multigravidae. Congenital malformations are usually associated with low birth weight. Studies by Prajapati, Patel and Aman Taskade showed a significantly higher incidence of anomalies in preterm babies than term babies. ${ }^{3,13,20}$ In present study $30.8 \%$ of the babies were born before 37 weeks of gestation. $47.9 \%$ of them were below $2.5 \mathrm{~kg}$.

Savaskar et al mentioned a history of previous abortion to be associated in mothers with anomalous babies. ${ }^{22,26}$ Gupta observed previous abortions (1.98\%) and preeclampsia $(3.9 \%)$ in mothers with anomalous babies. ${ }^{27}$ We have observed that $25.1 \%$ of the women had previous history of abortions, intrauterine demises and neonatal deaths. $12.4 \%$ of the mothers had diabetes and $5.3 \%$ of them had hypertension. The risk of congenital anomalies (excluding terminations) for gestational diabetes is 1.2 times higher than in the total population $(95 \%$ CI 1.1 $1.3) .^{28}$ We had a total number of 10,545 women with diabetes during the study period and the incidence of anomalies in diabetic women was $1.07 \%$ which is significantly high (p value 0.008). Several previous studies have shown that infants in breech presentation have more congenital malformations than infants born in vertex presentation. ${ }^{29,30}$ Out of 1,08,024 babies, 3684 of them were in breech presentation. 103 babies in breech presentation had structural anomalies, i.e. $2.8 \%$.

$20.9 \%$ of the anomalous babies had undergone intrauterine demise and $5.6 \%$ died within one week of delivery. According to some Western studies, one tenth of intrauterine demises have structural congenital anomalies. $^{31}$ In this study prevalence of congenital anomalies in intrauterine demise cases were $8.5 \%$. $3.92 \%$ of the neonatal deaths also had congenital anomalies.

The most common type of anomaly detected in the study was anomalies of urinary system (29.7\%). In another study conducted in the middle part of Kerala also showed an increased incidence of urogenital anomalies $(28.5 \%) .^{32}$ Gupta et al found the commonest anomaly was nervous system malformations $(41.9 \%) .{ }^{27}$ His findings were similar to that of Mashuda et al who noted $29.8 \%$ of nervous system malformations in their study. ${ }^{33}$ Congenital heart defects were the most commonly reported anomalies in the study Bhide $\mathrm{P}$ et al. ${ }^{34}$ These reports show that the pattern of prevalence of various anomalies varies in different parts of the country. Of the renal anomalies it is very important to notice that most of the anomalies are obstructive type $(60.8 \%)$. There were 24 cases of anencephaly and 46 cases of multiple congenital anomalies diagnosed in the later gestation which could have been terminated earlier.

\section{CONCLUSION}

In this study maternal diabetes was found to be associated with increased risk of structural anomalies. Therefore, prepregnancy counselling should be done for all diabetic patients. Routine anomaly scan should be an integral part 
of antenatal care so that early termination of lethal anomalies can be done. Proper registry of the cases helps to identify the magnitude of the problem, pattern of the distribution and also gives some clue regarding the aetiology. The limitations of the study are we did not include anomalies which were terminated before 24 weeks and chromosomal as well as metabolic disorders were not identified.

\section{Funding: No funding sources}

Conflict of interest: None declared

Ethical approval: Not required

\section{REFERENCES}

1. Dastgiri S, Sheikhzadeh Y, Dastgiri A. Monitoring of congenital anomalies in developing countries: a pilot model in Iran. InITCH. 2011;164:157-61.

2. Global Burden of Disease Pediatrics Collaboration, Kyu HH, Pinho C, Wagner JA, Brown JC, BertozziVilla $A$ et al. Global and National Burden of Diseases and Injuries Among Children and Adolescents Between 1990 and 2013: Findings From the Global Burden of Disease 2013 Study. JAMA Pediatr. 2016;170(3):267-87.

3. Patel ZM, Adhia RA. Birth defects surveillance study. Indian J Pediatr. 2005;72:489-91.

4. World Health Organization. Section on congenital anomalies. [Cited on 2016 September]. Available at http://www.who.int/mediacentre/factsheets/fs370/en/

5. Park K. Congenital malformations. In K Park's Text book of Preventive and Social Medicine, 15th ed. 2005:379-80.

6. Carmona RH. The global challenges of birth defects and disabilities. Lancet. 2005 Oct;366(9492):1142-4.

7. Christianson AL, Howson CP, Modell B. March of Dimes: global report on birth defects, the hidden toll of dying and disabled children. March of Dimes: global report on birth defects, the hidden toll of dying and disabled children. 2005. Available at http://www.marchofdimes.com/downloads/Birth_De fects_Report-PF.pdf. Accessed on 20 April 2016.

8. Prajapati VJ, Kacha AR, Kakkad KM, Damor PB, Nandaniya AM. Study of Congenital Malformation in Neonates Born at Tertiary Care Hospital. Natl J Community Med. 2015;6(1):30-4.

9. Penchaszadeh VB. Preventing congenital anomalies in developing countries. Community Genet. 2002;5:61-9.

10. Kar A, Preventing Birth Defects in India. Econo Politic Week. 2011;46(48).

11. Bhat BV, Ravikumara M. Perinatal mortality in India-Need for introspection. Indian J Matern Child Health. 1996;7:31-3.

12. Agarwal SS, Singh U, Singh PS, Singh SS, Das V, Sharma A, et al. Prevalence and spectrum of congenital malformations in a prospective study at a teaching hospital. Indian J Med Res. 1991;94:413-9.

13. Taksande A, Vilhekar K, Chaturvedi P, Jain M. Congenital malformations at birth in Central India: A rural medical college hospital based data. Indian $\mathbf{J}$ Hum Genet. 2010;16:159-63.

14. Chaturvedi P, Banerjee KS. Spectrum of congenital malformations in the newborns from rural Maharashtra. Indian J Pediatr. 1989;56:501-7.

15. Khatemi F, Mamoori GA. Survey of congenital major malformations in $10 / 000$ newborns. Iran J Pediatr. 2005;15:315-20.

16. Tomatir AG, Demirhan H, Sorkun HC, Köksal A, Ozerdem F, Cilengir N. Major congenital anomalies: A five-year retrospective regional study in Turkey. Genet Mol Res. 2009; 8:19-27.

17. Dutta V, Chaturvedi P. Congenital malformations in [7] rural Maharashtra. Indian Pediatr. 2000;37:9981001.

18. Mohanty C, Mishra OP, Das BK, Bhatia BD, Singh G. Congenital malformation in newborn: A study of 10,874 consecutive births. J Anat Soc India. 1989;38:101-11.

19. Biri A, Onan A, Korucuoglu Ü, Tiras B. Birth prevalence and distribution of congenital anomalies in a university hospital. Perinatol Dergisi. 2005; 13:86-90

20. Prajapati VJ, Kacha AR, Kakkad KM, Damor PB, Nandaniya AM. Study of congential malformations in neonates born at tertiary care hospital. Natl J Community Med. 2015;6(1):30-4.

21. Swain S, Agarwal A, Bhatia BD. Congenital malformation at birth, Indian Pediatr. 1994;31:118791.

22. Savaskar SV, Mundada SK, Pathan AS, Gajbhiye SF. Study of various antenatal factors associated with congenital anomalies born at tertiary health centre. Int J Recent Trends Sci Technol. 2014;12(1):82-5.

23. Parmar A, Rathod SP, Patel SV, Patel SM. Study of congenital anomalies in newborn. NJIRM. 2010;1(1):13-7.

24. Padma S, Ramakrishna D, Jijiya P, Ramana PV. Pattern of distribution of congenital anomalies in still born: a hospital based prospective study. Int $\mathbf{J}$ Pharma Bio Sci. 2011;2:604-10.

25. Kulshreshtha R, Nath LM, Upadhyaya P. Congenital Malformation in live born infants in a rural community. Indian Pediatr. 1982;19:1003-9.

26. Verma M, Chhatwal J, Singh D. Congenital malformations - a retrospective study of 10,000 cases. Indian J Pediatr. 1991;58:245-52.

27. Gupta S, Gupta P, Soni JS. A study on incidence of various systemic congenital malformations and their associations with maternal factors. Nat J Med Res. 2012;2(1):19-21.

28. Sharpe PB, Chan A, Haan EA, Hiller JE. Maternal diabetes and congenital anomalies in South Australia 1986-2000: a population-based cohort study. Birth Defects Res. 2005;73:605-11.

29. Mazor M, Hagay ZJ, Leiberman JR, Baile Y, Insler V. Fetal malformations associated with breech delivery. Implications for obstetric management. J Reprod Med. 1985 Nov;30:884-6. 
30. Hsieh YY, Tsai FJ, Lin CC, Chang FC, Tsai CH. Breech deformation complex in neonates. J Reprod Med. 2000 Nov;45:933-5.

31. Late Intrauterine Fetal Death and Stillbirth (Greentop Guideline No. 55);2010. Available at https://www.rcog.org.uk/en/guidelines-researchservices/guidelines/gtg55/

32. Wills V, Abraham J, Sreedevi NS. Congenital anomalies: the spectrum of distribution and associated maternal risk factors in a tertiary teaching hospital. Int J Reprod Contracept Obstet Gynecol. 2017 Mar 30;6(4):1555-60.

33. Mashuda F, Zuechner A, Chalya PL, Kidenya BR, Manyama M. Pattern and factors associated with congenital anomalies among young infants admitted at the Bugando Medical Centre, Mwanza, Tanzania. BMC Res Notes. 2014;7:195.

34. Bhide P, Gund P, Kar A. Prevalence of congenital anomalies in an Indian maternal cohort: healthcare, prevention, and surveillance implications. PloS one. 2016 Nov;11(11):e0166408.

Cite this article as: Jayasree $S$, D'Couth $S$.

Prevalence of congenital anomalies in a tertiary care centre in North Kerala, India. Int J Reprod

Contracept Obstet Gynecol 2018;7:864-9. 